\title{
HÁ uM SENTIDO, APESAR DE EU NÃO \\ O COMPREENDER
}

\author{
Marta Regina de Leão D'Agord* \\ Gabriel Inticher Binkowski** \\ Felipe Bücker Chittoni*** \\ Livia Zanchet ${ }^{* * * *}$
}

\section{RESUMO}

Este artigo enfoca a distinção entre abertura de sentido e esclarecimento do significado como um dos aspectos da relação entre a teoria do signo em Lingüística e Semiótica e a teoria do significante. Busca-se, também, analisar a contribuição da Semiótica para a teoria psicanalítica do sujeito. Dois textos, um literário e um clínico, contextualizam a análise da função da alteridade em relação ao sujeito; esta função poderá ser imaginária ou simbólica. Será simbólica na constituição do chiste. Os resultados do trabalho indicam que há proximidade entre escuta clínica, abertura de sentido e alteridade simbólica.

Palavras-chave: teoria psicanalítica do sujeito, significante, significado

\section{Abstract}

\section{THERE IS A MEANING, EVEN THOUGH I DONT'T GET IT}

This article focuses on the distinction between meaning's opening and clarification of the signified, as one of the aspects of the relationship between the theory of the sign in Linguistics and Semiotics to the theory of the signifier. The paper also searches to analyze the contribution of Semiotics to the psychoanalytical theory of the subject. Two texts, a literary and a clinical one, are the context to the analysis of the function of alterity for the subject, that may be imaginary

* Professora da Universidade Federal do Rio Grande do Sul - UFRGS.

** Acadêmico de Psicologia - Instituto de Psicologia - UFRGS.

*** Acadêmico de Psicologia - Instituto de Psicologia - UFRGS.

**** Acadêmico de Psicologia - Instituto de Psicologia - UFRGS. 
or symbolic. It will be symbolic in the constitution of a joke. Our results indicate that there is a relationship between clinical listening, symbolic alterity and meaning's opening.

Keywords: psychoanalytical theory of the subject, signifier, signified

Ao se perguntar pelo sentido de um enunciado, é possível seguir por dois caminhos: abertura de sentido ou esclarecimento de significado. Este trabalho trilha esses dois caminhos com o objetivo de contribuir para o estudo de uma relação que lhes é subjacente, a relação entre a teoria psicanalítica do sujeito e o campo da linguagem.

A teoria psicanalítica do sujeito interessa-se pelos efeitos das palavras sobre o eu, considerando que um desses efeitos é a constituição do sujeito. Essa hipótese do sujeito do inconsciente como um efeito insere-se no contexto da relação entre a cadeia significante e o discurso, isto é, no encontro que produz uma cisão entre enunciação e enunciado. Essa concepção de sujeito não é a subjetividade, pois o sujeito da relação de um significante ao outro tem o estatuto evanescente de uma formação do inconsciente, na medida em que é anunciado na fala, mas que não fala. Enquanto o sujeito que toma a palavra, o sujeito falante, este tem a solidez que é possível a uma subjetividade que sabe de si.

Pode haver linguagem sem que apareça sujeito. Mas, se há sujeito, uma alteridade dirigiu palavras a esse sujeito. A teoria psicanalítica do sujeito supõe uma alteridade, produzindo efeito de reconhecimento, para que alguém possa vir a ser um sujeito. Por alteridade podemos pensar um outro (alter), isto é, um outro enquanto sujeito constituído, por exemplo, a mãe, enquanto Outro imaginário para o infans. No entanto, a alteridade pode ser considerada como uma função da linguagem, enquanto função terceira, função de mediação para uma díade de interlocutores.

A função da alteridade na constituição do sujeito psíquico chama nossa atenção quando de sua ausência. Comparemos dois casos célebres de privação social na infância. O primeiro, um jovem encontrado na Alemanha no início do século XIX que mal sabia caminhar, escrevia o nome Kaspar Hauser e falava algumas palavras. Descobriu-se que Kaspar Hauser vivera sua infância isolado em um cárcere, mas escutara primordialmente algumas palavras provindas de um outro, um carcereiro. Assim, a experiência fundamental da fala provinda do outro, do semelhante, ele havia experimentado e provavelmente foi o que o ajudou em sua rápida inserção social. Mas isso não aconteceu ao segundo caso, conhecido como o menino selvagem de Aveyron (nomeado Victor), cuja privação de contato com uma alteridade na primeira infância dificultou sua inserção social. É claro que não 
estamos avaliando as diferenças em relação à educação, que Victor e Kaspar Hauser receberam posteriormente, pois citamos esses casos para demarcar essa relação primordial com uma alteridade.

A outra forma de alteridade, a da linguagem em relação aos falantes, deve ser analisada a partir a contribuição das ciências da linguagem. Vamos então analisar como o signo em lingüística e o signo em semiótica, quando transpostos para o cenário da teoria psicanalítica, permitem o avanço da formulação da teoria do sujeito. A relação entre sujeito e alteridade na tirada espirituosa permitirá analisar essa transposição.

\section{Do SIGNO AO SIGNIFICANTE}

Lacan toma de empréstimo a concepção de oposição sincrônica de um fonema a outro, da Lingüística de Saussure, e a concepção triádica de signo para Peirce. Em relação ao signo de Saussure, o efeito da transposição é a idéia de que um significante somente se define pela relação com outro significante. Nesse encontro entre Lingüística e Psicanálise, esta entrou com a temporalidade do só-depois (o Nachträglich freudiano), pois, se é na anterioridade da relação entre um significante e outro que se produz o sentido, este somente acontece no só-depois.

Lacan destaca, da teoria do signo de Saussure, duas propriedades do significante: (1) os significantes podem ser reduzidos a elementos diferenciais, os fonemas, isto é, o sistema sincrônico dos acoplamentos diferenciais, necessários ao discernimento dos vocábulos numa língua dada; (2) esses elementos se compõem de acordo com as leis de uma ordem fechada. Na gramática e no léxico, são somente as correlações do significante ao significante que lhes dão o padrão de toda busca de significação.

Um exemplo nos ajuda a entender. Trata-se do exemplo da criação analógica: o verbo "morcegar" a partir de morcego, junta mais um par a uma série onde já se encontram, almoço, almoçar. Eis a idéia de ordem e regularidade no âmbito de uma organização de conjunto, uma língua. Uma unidade pode ser substituída por outra porque ela está relacionada a um conjunto. Essa ordem, em um sistema de língua, Lacan a transpõe para a lei de articulação dos significantes. Mas, para isso, inclui não apenas as palavras que já existem na língua, mas todas as formas possíveis de articulação entre significantes. O tesouro dos significantes é tesouro porque sempre está sendo descoberto e nunca será totalmente descoberto.

A essas duas propriedades do significante Lacan acrescenta mais uma: quando encadeados na fala, os significantes sempre se antecipam ao sentido pelo efeito de só-depois: "É o que se vê, no nível da frase, quando ela é interrompida antes do 
termo significativo: Eu nunca..., A verdade é que..., Talvez, também... Nem por isso ela deixa de fazer sentido, e um sentido ainda mais opressivo na medida em que se basta ao se fazer esperar (Lacan, 1957/1998: 505).

A cadeia significante vai permitir que todas as possibilidades se antecipem a uma escolha do sujeito. Nessa antecipação de sentido, mesmo que o sujeito não chegue a terminar sua fala, uma indicação de que há um sentido para essa interrupção da fala já será suficiente para o efeito de abertura de sentido.

Para analisar o conceito de signo na Semiótica, optamos por trabalhar com a obra Fundamentos da teoria dos signos, onde Morris (1938) sistematiza a semiótica de Peirce. É deste ensaio a definição de Semiótica como o estudo da relação da mente humana em relação aos signos através do processo de semiose, isto é, o processo de mediação em que algo funciona como um signo. Este processo, numa tradição que já vem dos gregos, envolve quatro fatores: (1) o vínculo sígnico, aquilo que atua como um signo; (2) o designatum, aquilo a que o signo se refere, mesmo que não seja algo existente. Quando aquilo que o signo designa tem existência, trata-se de um denotatum. Quando perguntamos quais são os objetos designados por determinado signo ou palavra, estamos nos referindo a espécies de objetos ou classes de objetos, estamos no nível semiótico do designatum. Mas, quando perguntamos pelos elementos de uma classe, estamos nos referindo aos denotata; (3) o interpretante, o efeito sobre um intérprete em virtude do qual a coisa em questão é um signo para esse intérprete; (4) o intérprete. Esses termos explicitam os fatores implícitos na afirmação habitual de que um signo refere-se a algo para alguém.

Em Semiótica, o termo "signo" somente se aplica a algo que faz parte de um sistema de signos. De modo que cada signo tem relaçôes com outros signos, pois que aquilo para o qual o signo prepara o intérprete para se dar conta só pode ser estabelecido em termos de outros signos. Essa relação formal dos signos uns com os outros é chamada de dimensão sintática da semiose. Além da dimensão sintática, as outras duas dimensões da semiose são a dimensão semântica e a dimensão pragmática. A dimensão semântica envolve a relação dos signos com os objetos a que eles se aplicam. A dimensão pragmática refere-se às relações entre os signos e os intérpretes, ou seja, o que o signo expressa para um intérprete.

Portanto, Santo Agostinho se refere à semântica quando, na sua obra Confissões, relata que, antes de aprender a falar, ele não conseguia exteriorizar o que desejava, nem ser compreendido por aqueles a quem se dirigia. E que, para aprender a falar, ele procedeu da seguinte forma: "Via e notava que davam ao objeto, quando o queriam designar, um nome ou eles pronunciavam. Por esse processo retinha pouco a pouco as palavras convenientemente dispostas em várias frases e freqüentemente ouvidas como sinais de objetos (Santo Agostinho, 1988: 31-32). 
O que Santo Agostinho fez para aprender a falar foi seguir o que já estava instituído e isso que já está instituído é o signo. Trata-se da dimensão semântica da semiose, isto é, a relação do signo com os objetos a que os signos se aplicam.

Mas, se essa relação de domínio sobre as palavras existe no universo da ciência, da palavra escrita e das proposiçóes logicamente ordenadas de que se ocupa a semiótica, não é este o caso na fala. Ao falar, corre-se o risco do equívoco, do malentendido. O objeto da Semiótica não é o discurso e sim o processo pelo qual um alguém é capaz de supor significados onde há significantes. Enquanto esse alguém opera, não está em questão uma abertura de sentido, isto é, a abertura que apareceria a partir de uma interrogação como a seguinte: "será que isso quer dizer outra coisa, mesmo que de momento eu não entenda, isto é, eu não tenha um significado a dispor?".

Em "Posição do inconsciente" (1964/1998), Lacan mostra que é a inserção do sujeito que diferencia a sua teoria do significante da teoria dos signos. Ele reconhece que os signos são plurivalentes e representam alguma coisa para alguém; mas, desse alguém, o status é incerto. Se há informação, há alguém que recebe essa informação, mas não há ainda um sujeito.

Enquanto que o registro do significante institui-se justamente pelo fato de um significante representar um sujeito para outro significante. Essa é a estrutura, sonho, lapso e chiste, de todas as formações do inconsciente. E é também o que explica a divisão originária do sujeito. Produzindo-se o significante em lugar do Outro ainda não discernido, ele faz surgir ali o sujeito do ser que ainda não possui fala, mas ao preço de cristalizá-lo. O que ali havia de pronto para falar - nos dois sentidos que o imperfeito do francês dá ao il y avait [havia], o de colocá-lo no instante anterior: lá estava e não está mais; porém também no instante posterior: por pouco mais lá estava por ter podido lá estar - o que lá havia desaparece, por não ser mais do que um significante (Lacan, 1964/1998: 854).

É a partir do encadeamento de significantes que se produzirá um sujeito que será suporte e efeito da fala. Suporte porque é ele que fala, efeito porque sua fala diz quem ele é. O sujeito divide-se entre aquele que fala o enunciado e aquele que é falado neste mesmo enunciado. Ser sujeito da fala é ser sujeitado aos equívocos da linguagem, ou seja, uma enunciação pode corresponder a mais de um sentido, dependendo do contexto, mas isso produz uma falha na linguagem, uma falta, um intervalo variável entre uma fala e sua significação possível.

O significante, afirma Lacan (1964/1998) “joga e ganha antes que o sujeito constate isso, a ponto de, no jogo do Witz, do chiste, por exemplo, ele surpreender 
o sujeito. Com seu flash, o que ele ilumina é a divisão entre o sujeito e ele mesmo" (1964/1998: 854).

O chiste ou dito espirituoso pode ser considerado um modelo de relação triádica, isto é, de três posições, na qual um significante produz um sujeito para outro significante. É aqui que pretendemos uma retomada desse diálogo entre Semiótica e teoria psicanalítica sujeito, buscando estabelecer uma comparação inspirada na análise dos modelos ternário, binário e unário.

\section{UNÁRIO, BINÁRIO E TERNÁRIO}

Dufour (2000) resgata a contribuição de Peirce para a fundamentação da relação entre os modos unário, binário e ternário de pensamento. Esses modos constituem uma categorização da atividade espontânea e dos processos mentais do homem na língua. Peirce ${ }^{1}$ descreve três modos de ser, a saber, "primeiridade", "segundidade" e "terceiridade". Primeiridade é a concepção do ser ou do existir independentemente de qualquer outra coisa. Segundidade é a concepção do ser relativo a qualquer outra coisa. Terceiridade é a concepção da mediação pela qual um primeiro e um segundo são relacionados. Dufour (2000) compara essas categorias fenomenológicas de Peirce às formas verbais, ou seja, eu, eu-tu e eu-tu-ele e às respectivas formas unária, binária e trinitária (ou ternária).

Ao analisar o "eu" na fórmula "é eu quem diz eu", Dufour (2000) observa que o eu se produz numa forma unária, sui-referencial cujas implicações são as seguintes: a forma de onde emana o eu é, ao mesmo tempo, toda-suficiente e toda-insuficiente. E compara esta à primeiridade de Peirce.

A segundidade de Peirce seria, por sua vez, homóloga à díade eu-tu. O segundo é precisamente o que não pode ser sem o primeiro. Uma coisa não pode ser outra, negativa ou independente, sem um primeiro com relação ao qual ela será outra, negativa ou independente.

As qualidades da tríade "eu-tu/ele" podem ser enunciadas a partir da posição do terceiro, o "ele" como um introdutor da ordem: para que dois estejam aqui, basta que um outro estivesse ali. É precisamente em termos de "lei" que Peirce descreve o ternário. Como na tríade das pessoas verbais, o terceiro põe em relação o primeiro e o segundo. É necessário um terceiro para que haja um primeiro e um segundo e esta relação a três é impossível de ser decomposta em relações diádicas.

A contribuição do trabalho de Dufour (2000) é mostrar uma continuidade entre o que é unário, binário e ternário; por exemplo, o ternário estaria presente no binário, mesmo que essa presença fosse velada. Isto é, em uma enunciação, seria possível encontrar as manifestações dessas três formas, as quais não seriam absolutas, mas passageiras, como o é a forma espontânea da enunciação. 
Como esse modelo semiótico poderia produzir uma contribuição à teoria psicanalítica do sujeito? Seria através da pergunta pela presença do ternário na enunciação, mesmo quando este não é o esperado? Vamos então tomar o dito espirituoso como modelo da relação ternária. Prosseguiremos com o apoio de um texto literário e de um texto clínico.

O texto literário escolhido é "Famigerado", do escritor João Guimarães Rosa (1962/1990). Neste texto, há o relato de um diálogo entre o narrador e um visitante. $\mathrm{O}$ narrador, que se apresenta como médico no sertão, relata a chegada inesperada de quatro cavaleiros, um dos quais toma a palavra. Aos poucos, o narrador percebe que se trata de famoso pistoleiro, de nome Damásio, e que este deseja esclarecer o significado de uma palavra. Destacamos um extrato do diálogo:

Vosmecê agora me faça a boa obra de querer me ensinar o que é mesmo que é: fasmisgerado... faz-me-gerado... falmisgeraldo... familhas-gerado...?

-Famigerado?

- Sim senhor.

-Vosmecê declare. Estes aí são de nada não. São da Serra. Só vieram comigo, pra testemunho.

Só tinha de desentalar-me. O homem queria estrito o caroço: o verivérbio.

- Famigerado é inóxio, é "célebre", "notório", "notável".

- Vosmecê mal não veja em minha grossaria no não entender. Mais me diga: é desaforado? É caçoável? É de arrenegar? Farsância? Nome de ofensa?

- Vilta nenhuma, nenhum doesto. São expressões neutras, de outros usos.

- Pois... e o que é que é, em fala de pobre, linguagem de em dia-de-semana?

- Famigerado? Bem. É: "importante", que merece louvor, respeito.

- Vosmecê agarante, pra a paz das mães, mão na Escritura?

Se certo! Era para se empenhar a barba. Do que o diabo, então eu sincero disse: - Olhe: eu, como o sr. me vê, com vantagens, hum, o que eu queria uma hora destas era ser famigerado - bem famigerado, o mais que pudesse!

- Ah, bem! - soltou, exultante (Guimarães Rosa, 1962/1990:104-105)².

$\mathrm{Na}$ fala do visitante, "fasmisgerado, faz-me-gerado, falmisgeraldo, familhasgerado", os significantes sucedem-se por um deslocamento homofônico. Nessa contigüidade entre os significantes, antecipam-se possibilidades, mas nenhuma é sancionada. Caso uma delas fosse sancionada, teríamos a possibilidade de constituição de um dito espirituoso ou chiste.

A fala do visitante é dirigida a um Outro. Um Outro que está no lugar do tesouro dos significantes. Esse tesouro, considerado ao pé da letra, pode ser confundido com um dicionário. Entretanto, tomado metaforicamente, pode ser considera- 
do como todas as possibilidades de relação entre os fonemas, mesmo aquelas que soam estranhas a uma língua. Nesse segundo caso, o narrador poderia ter se interrogado sobre o sentido de "fasmisgerado, faz-me-gerado, falmisgeraldo, familhas-gerado". Mas, ao responder, ele esclarece o significado da palavra "Famigerado". Nesse caso, o Outro é o dicionário e o narrador é convocado a responder desde esse lugar. O narrador enuncia as acepções de "Famigerado" tais como constam no dicionário; por exemplo, famoso, célebre. No entanto, essas palavras não geram efeito em Damásio. É então que o seu interlocutor lança mão do recurso imaginário. Se o simbólico, enquanto recurso às palavras, não tem eficácia, é preciso apelar ao recurso imaginário. Esse recurso será a imagem proposta: "Olhe: eu, como o sr. me vê, com vantagens, hum, o que eu queria uma hora destas era ser famigerado - bem famigerado, o mais que pudesse!..." (Rosa, 1962/1990: 105).

Este recurso imaginário pode ser analisado com base no esquema L de Lacan (1957/1998: 58). Esse esquema (ver esquema original em anexo) permite-nos fazer a diferenciação entre relação imaginária, sustentada na imagem de si e do outro, e relação simbólica, sustentada na alteridade da linguagem. Podemos então situar, na diagonal da relação imaginária, a e a', Damásio e o moço do governo, respectivamente. $\mathrm{O}$ narrador é convocado a ocupar o lugar de Outro, mas um Outro imaginário, não submetido à falta.

O moço do governo como outro imaginário: aquele que "melhor seria se fosse embora", aquele que vem dirigir a Damásio uma palavra que é tomada como algo persecutório. Devido à ausência de uma alteridade simbólica, o que o outro imaginário diz é especularmente tomado como revelação do que se é. Ocorre então um curto-circuito entre a e a', entre Damásio e o moço do governo, entre eu e o outro. Será que me vejo desde o olhar do outro? Será que sou aquilo que o outro diz de mim? Será que o outro quer a minha destruição? Eu quero o desaparecimento do outro. Ou eu ou o outro. Mas seria possível encontrar aí o modelo ternário, mesmo velado? Sim, representado pelo dicionário, o terceiro está presente no discurso de Damásio; ele opera desde que suposto em um Outro, mas um Outro imaginário que tudo sabe.

O apelo a um Outro, neste caso, representado pelo doutor que conhece o dicionário, a quem se dirige Damásio para recuperar sua imagem. O personagem Damásio buscaria um interlocutor na posição de grande Outro para, a partir daí, surgir uma sanção. Essa sanção seria como um ponto de estofo que deteria o deslizamento incessante de significantes no lugar do código. Somente a fala do interlocutor, "eu queria ser Famigerado", produziu esse efeito. Agora, Damásio pode se reconhecer no traço "famigerado". Mas esse reconhecimento é através da via imaginária, um Outro que conhece as palavras do dicionário, que representa ou está no lugar do conhecimento. 
Nesse caso, é como se ocorresse uma suplência do simbólico pelo imaginário. A falta, isto é, a equivocidade entre as palavras, não é aceita por Damásio, que demanda que essa falta seja suprida pela garantia da imagem do outro.

$\mathrm{O}$ equívoco de linguagem caracteriza um intervalo, uma falta, uma hiância como função inerente ao tesouro dos significantes: A falta de biunivocidade, a não-correspondência termo a termo. O lugar ocupado por Damásio nesta narrativa é o de representar aquele que rejeita a castração, isto é, não admite a inexistência de um Outro do Outro, de um garantidor que supra a falta.

Vamos analisar um outro caso, onde o terceiro enquanto alteridade da linguagem, aparentemente ausente, revela-se mesmo assim. Trata-se do caso de uma criança em análise e da escuta da mensagem por parte da analista. Situamos o caso na diferenciação entre código e mensagem desenvolvida por Lacan. Quando um discurso não é cruzado por uma cadeia significante, fica restrito ao código. Para ilustrar esta idéia, Laznik-Penot (1997) apresenta um caso clínico - o caso Louise. Esse caso mostra como é necessário que o discurso se dirija a um Outro e que este possa testemunhar que se trata efetivamente, para ele, de uma mensagem. Eis os dois pontos de cruzamento do discurso com a cadeia significante, sendo que a mensagem, o segundo cruzamento, constitui um efeito, no só-depois, do primeiro cruzamento.

Louise chega para atendimento com quatro anos. A menina vivencia episódios enuréticos freqüentes, perde com facilidade o eixo de sustentação de seu corpo, caindo como uma boneca de pano, seus sapatos saem regularmente de seus pés. A tomada de seu corpo num circuito pulsional está claramente em falta. Diferentemente de outrora - antes de sofrer qualquer intervenção terapêutica - a menina anda e fala um pouco, ainda que de modo bastante peculiar. Dentre suas poucas (e muitas vezes incompreensíveis) palavras, Louise reproduz fragmentos de canções infantis que ela costuma ouvir em sua casa. Durante o tratamento, a analista, sempre que surpreendida por uma de suas vocalizaçóes, busca encontrar uma representação possível para seu discurso, apoiando-se também nas falas dos pais da menina. A analista relata que estes, até então, nunca haviam atribuído valor de mensagem ao que era dito pela filha. É especialmente nas cantigas infantis pelas quais Louise demonstra muito interesse e ouve repetidas vezes em sua casa que Laznik-Penot vai encontrar o suporte dos significantes expressos no decorrer das sessões. Expressões como "Eu sou Lou, o pequeno lobo das estepes", "estava à janela", "filha do rei" são jogadas no espaço da sessão e tomadas pela analista como possibilidades de advento de significantes. Ao questionar os pais da menina acerca dessas e outras expressões, descobre que são todas pequenos pedaços das canções que ela ouve em um aparelho que possui em casa. Canções essas que falam de "uma menina”, "da filha do rei” de "um bebê formidável! A ver!. A 
ver!”. A analista descobre que essas palavras de Louise relacionam-se com a fita "Gargântua contado para as crianças". No entanto, em vez do primeiro grito do bebê Gargântua, "A beber! A beber!”, Louise exclama: “A ver! A ver!”.

Ao escutar essa deformação do texto, a psicanalista, tem duas alternativas. Uma primeira alternativa seria desconsiderar a importância do que é dito, isto é, tomar essa deformação do texto como algo sem significação, seria como dizer: “isso não quer dizer nada”. Uma segunda alternativa, e que será a alternativa seguida pela psicanalista, é a de se colocar como a terceira pessoa na constituição de um chiste, aquela que se deixa siderar, surpreender, espantar.

Essa sideração testemunha um vazio interior, uma não-completude, uma falta - característica que tem fundamentalmente de ser atribuída ao Outro para que possa se dar a constituição do sujeito. $\mathrm{O}$ reconhecimento primeiro da analista poderá então seguir adiante nas pessoas dos pais, quando estes também conseguirem atribuir significação à fala de sua filha, sem tomá-la apenas como um estribilho.

Durante o tratamento, a analista colocou-se no lugar do Outro que se deixa siderar pelas palavras de Louise, permitindo assim que o enunciado de Louise ultrapasse o lugar de código. É essa possibilidade de assumir, como analista, o lugar do Outro primordial - reconhecendo valor significante a toda produção da criança e antecipando o sujeito a advir - que se encontra no cerne do trabalho psicanalítico nesses casos (Laznik-Penot, 1997). É acreditando na emergência de uma mensagem onde só há um grito, uma sonorização, que o analista realiza uma escuta clínica, permitindo à criança encontrar aquilo que não pôde vivenciar durante seus primeiros momentos de existência.

Com a teoria psicanalítica podemos, portanto, atingir a seguinte formulação da relação com a linguagem. $\mathrm{O}$ inconsciente encontra-se no nível da linguagem, dos elementos (stoicheion), das letras da língua, do código. Mas a fala é ato singular de um sujeito. A expressão bíblica In principio erat verbum trata da linguagem e não da fala. E a primeira palavra aparece encarnada na fala da mãe. É por isso que a mãe encarna o grande Outro primário (Autre) para o infans. É nesta fala que o infans tem o primeiro encontro com a radical alteridade do significante.

Ou seja, para o infans, a relação entre significantes ainda não produz significações, toda fala é puro significante. É essa alteridade radical dos significantes que instaura o sujeito nesse situs que é o inconsciente. Essa alteridade está dada pela relação entre um significante com o outro à revelia do sujeito. Isso significa que o Outro é o tesouro inconsciente dos significantes e que as leis do inconsciente são as leis do significante, ou seja, da articulação de um significante com outro, das relações que os significantes vão efetuando na medida em que se situam antes ou depois do outro em uma enunciação. Um ato de fala, na temporalidade, na 
diacronia, é antecipado na linguagem pelas leis de articulação sincrônica dos significantes entre si. Assim, a fala não se antecipa à linguagem, mas a linguagem antecipa a fala; logo, antecipa o sujeito.

A linguagem é necessária, mas não suficiente para que surja um sujeito. A linguagem é apenas código enquanto não houver uma sanção de um Outro, de uma alteridade, que, mesmo não compreendendo, possa dizer: há algo aí, há uma mensagem aí. Assim, na diferença entre linguagem e fala, é importante também fazer a distinção entre "esclarecimento de significado" e "abertura de sentido". Vamos então comparar o caso "Famigerado" com o caso "Louise". O primeiro caso mostra um dito espirituoso que não aconteceu. A demanda de esclarecimento de significado impediu que a alteridade escutasse a abertura de sentido para além do significado possível. O segundo caso ilustra bem como um dito espirituoso é construído na escuta. Pois foi o espanto da alteridade o que permitiu que se instituísse o Outro simbólico, e não imaginário. Mas houve espanto porque já havia uma mediação simbólica, porque a alteridade já estava situada em relação a um terceiro, a uma falta, exemplificada pela formulação "não sei o que significa isso, mas deve haver algum sentido". Eis a função ternária da alteridade como condição para a mediação entre o um e o outro. Essa função somente se encontra no campo da linguagem, no campo do simbólico.

Podemos então formular que a relação de continuidade entre os modelos semióticos unário, binário e trinitário tem a contribuir para a teoria psicanalítica do sujeito e para a clínica que se funda nesta; levando inclusive à relativização da noção de estrutura. Consideramos uma estrutura como estando constituída a partir da relação com a falta, com a hiância, com o espaço entre uma palavra e outra, pela relação do terceiro, entre eu e o outro. Uma estrutura discursiva, entretanto, aparece e desaparece na relação do sujeito com a alteridade enquanto possibilidade de uma língua, isto é, quando o sujeito consegue escutar seu ato falho, ou quando um outro escuta essa fala e sanciona: "há um sentido aí, apesar de eu não o compreender".

\section{REFERÊNCIAS BIBLIOGRÁFICAS}

Banks-Leite, L. e Galvão, I. (Orgs.). (2000). A educação de um selvagem: as experiências pedagógicas de Jean Itard. São Paulo: Cortez.

Dufour, D.-R. (2000). Os mistérios da trindade. Rio de Janeiro: Companhia de Freud.

Lacan, J. (1957). A instância da letra no inconsciente ou a razão desde Freud. Em Escritos (pp. 496-533). Rio de Janeiro: Jorge Zahar, 1998.

(1957). O Seminário sobre "A carta roubada”. Em Escritos (pp. 13-66). Rio de Janeiro: Jorge Zahar, 1998. 
(1964). A posição do inconsciente. Em Escritos (pp. 843-864). Rio de Janeiro: Jorge Zahar, 1998.

Laznik-Penot, M.-C. (1997). Rumo à palavra: três crianças autistas em psicanálise. São Paulo: Escuta.

Morris, C. (1938). Fundamentos da teoria dos signos. Tradução de Antonio Fidalgo. Disponível em http://bocc.ubi.pt/ fidalgo/semiotica/. Acesso em 05/10/2006.

Rosa, G. J. (1962). Famigerado. Em Seleção de textos (pp. 101-105), $3^{a}$ ed. São Paulo: Nova Cultural, 1990.

Santo Agostinho. (1988). Confissões. Petrópolis: Vozes.

Wassermann, J. (1996). Kaspar Hauser. Rio de Janeiro: Topbooks.

\section{NoTAS}

1 Seguimos aqui as referências de Dufour (2000) a Peirce.

2 Apresentamos aqui um resumo com os momentos mais importantes do diálogo entre o narrador e visitante, tal como consta nas páginas 104-105 do texto de Guimarães Rosa.

\section{ANEXo}

\section{O Esquema}

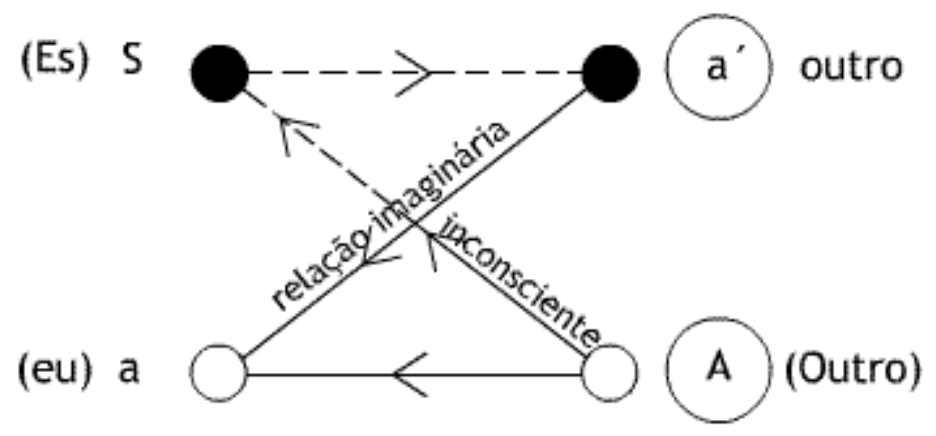

Recebido em 05 de janeiro de 2006 Aceito para publicação em 09 de junho de 2006 